\title{
METODOLOGIA DA PESQUISA EM EDUCAÇÃO: ANALÍTICA E DIALÉTICA
}

\author{
Prof. Dr. Antonio Edmilson PASCHOAL*
}

\section{Resumo}

Este artigo surgiu no contexto de uma discussão sobre Metodologia da Pesquisa em Educação, com o propósito de apresentar alguns de seus pressupostos básicos - a Analítica e a Dialética - a partir da idéia de que não se pode dissociar, em tal pesquisa, a produção do conhecimento de sua explicitação.

Palavras-chave: Educação - Metodologia - Analítica - Dialética.

\section{Abstract}

This article emerges from a discussion about Methodology for the Research in Education. It intends to present some of its basic assumptions - the Analytics and the Dialectic - since it is not possible to dissociate the production and the explanation of knowledge, in this specific kind of research.

Key words: Education - Methodology - Analytics - Dialectic.

* Professor/Pesquisador do Programa de Pós-Graduação em Educação da PUCPR. Diretor do Curso de Filosofia da PUCPR. 


\section{Introdução}

Existem vários empregos para o termo método. 0 mais conhecido é aquele que o toma a partir de sua raiz etimológica (do grego methodos e do latim methodu) para expressar a idéia de caminho. Dessa primeira acepção do termo, seguem-se outras que ampliam seu significado inicial, passando a incluir os procedimentos adotados para se chegar a certos resultados, ou a associá-lo não à obtenção de um resultado, mas à sua apresentação, quando o termo passa a designar uma boa ordem na disposição dos raciocínios, apresentados tanto de forma oral quanto escrita.

Com a necessidade que se coloca a partir do século XVII, de se garantir verdades sem o recurso à autoridade, como era comum em períodos anteriores, o método tem sua importância ampliada, deixando de ser considerado apenas como caminho ou conjunto de procedimentos que conduziria a uma meta ou a uma verdade, para assumir o status de garantia dessa verdade, especialmente da verdade produzida pela ciência.

Ao se tomar essas acepções básicas do termo método, há que se apontar ao menos um problema e um limite que elas possuem. O problema é que elas apresentam uma explícita separação entre fins e meios, e entre a produção de uma tese e a sua explicitação. O limite dessas concepções de método está em sua aplicação fortemente restrita àquele tipo de pesquisa que procede por hipótese e verificação (experimentação), muito próprio às ciências naturais. Caso em que se teria, no texto final - em um relatório de pesquisa - a apresentação minuciosa dos procedimentos como garantia de verdade (validade) de seus resultados.

Deixando de lado, neste momento, os problemas que essas utilizações iniciais podem comportar e considerando apenas algumas necessidades próprias à pesquisa e produção de textos em Educação, nos propomos a dar um passo para além das fronteiras próprias a essas concepções sem, no entanto, deixar de considerá-las como pontos de partida para nossas reflexões.

Uma questão que pode ser tomada de início é que, em Ciências Humanas, não se pode dissociar uma tese de sua explicitação. Nesse sentido, Victor Goldschmidt afirma, quando trata da produção de sistemas filosóficos: "doutrina e método, com efeito, não são elementos separados. O método se encontra em ato nos próprios movimentos do pensamento filosófico, e a principal tarefa do intérprete é restituir a unidade indissolúvel desse pensamento que inventa teses, praticando um método". (1970, p. 141)

Uma idéia (uma intuição talvez) não pode existir e tornar-se pública sem um método. Em uma dissertação tem-se, por um lado, uma tese que se movimenta, explicitando-se por meio de um método e, por outro, um método em ação que, sendo praticado, permite que a tese exista.

Um método, nesse sentido, não designa uma teoria ao lado da teoria, 
tampouco a formatação de um discurso, mas a formação e a explicitação de uma idéia que não estará pronta enquanto não for exposta por meio de uma codificação, do encadeamento, que são as estruturas do texto ou, caso se queira, das "articulações do método em ato" (GOLDSCHMIDT, 1970, p. 143). Ao leitor caberá refazer os movimentos produzidos pelo autor, o "tempo lógico" de sua tese, possível apenas na obra escrita.

A partir da constatação de que método e resultado não se separam, a opção por um método passa a configurar-se como uma decisão tão importante quanto a escolha do objeto da pesquisa. Pode-se mesmo dizer que, em ambos os casos, trata-se da mesma escolha, uma vez que os resultados pretendidos não podem ser dissociados do método escolhido.

As considerações que se seguem sobre a analítica e a dialética têm por objetivo colocar ao estudante, que, necessariamente, precisa escolher um método, algumas ponderações que permitam associar à escolha, também a necessidade de avaliação do método, tanto por seu caráter de pressuposto de leitura da realidade, quanto por sua viabilidade para a explicitação de uma tese.

Entendidos enquanto modelos metodológicos, analítica e dialética são opostos tanto no que se refere a seus pressupostos de leitura da realidade (de objetos de estudo), quanto na forma de explicitar teses. Essa oposição tem suas raízes remotas na Grécia Antiga, em duas formas contrárias de conceber o mundo, defendidas por Heráclito (de Éfeso - final do século VI a.C.) e por Parmênides (de Eléia - final do séc. VI e início do séc. V a.C.).

Heráclito observou que neste mundo tudo está em constante processo e nada permanece para sempre (não se pode atirar o mesmo giz no mesmo rio duas vezes). Sendo assim, falar de uma essência do mundo seria falar de seu constante vir-a-ser. Não menos importante é o conhecimento (episteme) desse processo de efetivar-se e dissolver-se das coisas - do próprio movimento - e não o conhecimento de algo particular e perecível (doxa), que seria perda de tempo.

Parmênides, por sua vez, não admite que neste mundo haja mudanças substanciais. $\mathrm{O}$ mundo efetivamente não pode se transformar, caso isso ocorresse, em função da infinidade do tempo, já teria chegado a um termo ou, o que é mais provável, teria se destruído, pois mover-se seria desgastar-se. Segue-se, portanto que, para ele, as mudanças são apenas aparentes, e o que interessa ser conhecido é aquilo que permanece sempre, a identidade do mundo e das coisas, que não se altera. Nesse sentido, o conhecimento que interessa (episteme) se dá pelo olhar sobre a identidade da coisa que é imutável, e qualquer conhecimento que se produza a partir do que é aparente e ilusório, como é o caso, é apenas ilusão (doxa) e perda de tempo.

Considere-se, por exemplo, a palavra eu tomada nessas duas perspectivas. Na primeira, a palavra eu designaria um momento em um processo 
dinâmico, o resultado de conflitos vividos e a base para novas vivências; algo fluente, que se altera e do qual somente se tomaria um momento isolado para entender o processo de mudanças. Na segunda, a palavra eu designaria uma identidade que não se altera substancialmente, embora possa sofrer mudanças. Conhecer este eu seria, neste último caso, buscar essa identidade que, independente do tempo, mantém-se sempre.

Grosso modo, pode-se dizer que com Heráclito e Parmênides tem-se, de forma embrionária, os dois princípios metodológicos que estamos estudando, uma vez que dessas concepções de objeto de estudo, passa-se a exigir ora um método que o apreenda em seu movimento ora outro, que o exponha em seus aspectos constitutivos. Parece claro que no primeiro caso o modelo metodológico deverá ser dialético e, no segundo, analítico. A precocidade de tais conclusões, no entanto, exige que se avance um pouco mais no Mundo Grego, no qual se encontram mais alguns componentes que permitem chegar a uma primeira definição de dialética e de analítica.

Embora Sócrates conceba a Filosofia como a arte de estabelecer diálogos, é com Platão (que denomina seus escritos de Diálogos) que está relacionada a primeira utilização do termo dialética?? Em um diálogo, no entanto, embora existam duas posições - tese e antítese - em um embate, não se tem, necessariamente, uma dialética, pois nem sempre, ao final de um debate, chega-se a uma síntese.

Há vários resultados possíveis no desfecho de um diálogo. Um deles é que ambos os debatedores podem permanecer inalteráveis em suas convicções. Com isso, o que se teve foi apenas um duplo monólogo e não dialética. Outro é que uma das posições saia vencedora, eliminando a concorrente e, dessa forma, com a eliminação (extermínio) de uma das partes, também não se produz dialética. Há ainda um terceiro resultado possível: ambos os debatedores admitirem a falsidade de suas teses. Nesse caso, se não houver perdas irreparáveis nas duas partes, é possível que se tenha uma síntese por superação (Aufhebung) dos opostos. Somente sob essa condição haveria uma dialética.

Sobre a possibilidade de se ter uma dialética em Sócrates e Platão, existe praticamente o consenso de que, com ambos, não há uma síntese, como ocorre com Hegel. Portanto, na Grécia Antiga, dialética seria apenas a prática do diálogo. Nada impede, no entanto, de se tomar a dialética em Sócrates como um método educativo, e a síntese - que não aparece nos diálogos seria a virtude obtida com a arte do debate. No caso de Platão, a síntese, que é o Sumo Bem, é atingida pela dialética. Segundo Cirne-Lima (1977, p. 37-41), esta síntese não somente existe, permitindo que se entenda a dialética platônica na acepção mais rigorosa do termo, como é indispensável para a compreensão de seu pensamento. O fato é que ele não a oferece aos seus leitores nos diálogos escritos para o grande público (aqueles que são conhecidos por nós 
hoje), a não ser esporadicamente, na forma de mitos, como o Mito da Caverna, na República (Platão, 1996, p. 317ss).

Quanto ao termo analítica, é utilizado pela primeira vez para designar alguns escritos de Aristóteles que tratam da Lógica (Primeiros Analíticos e Segundos Analíticos). Seguindo a tradição que se constitui a partir de Aristóteles, o termo indica um sistema que procede por análise, ou seja, por meio da separação de um todo em suas partes para que, no estudo em separado das partes e na busca da inter-relação entre elas, se tenha uma melhor compreensão do todo.

A analítica em Aristóteles aplica-se inicialmente a proposições, que são frases compostas de sujeito e predicado e que podem ser analisadas, por exemplo, quanto aos seus quantificadores (individual, particular, universal), e por serem afirmativas ou negativas.

Além do estudo de proposições isoladas, Aristóteles ocupou-se também de conjuntos bem concatenados de proposições, a que ele chamou de silogismos. Da mesma forma que uma proposição, também um silogismo pode ser decomposto, avaliado e declarado verdadeiro ou falso por meio da análise de suas partes. Por exemplo, em um silogismo composto de duas premissas iniciais verdadeiras, a proposição de conclusão será sempre verdadeira. $\mathrm{O}$ exemplo mais conhecido de silogismo é o seguinte:

$\begin{array}{ll}\text { Todo homem é mortal. } & \text { (Premissa maior) } \\ \text { Pedro é homem. } & \text { (Premissa menor) } \\ \text { Logo, Pedro é mortal. } & \text { (Conclusão) }\end{array}$

Da análise dos silogismos em separado, Aristóteles passa para uma classificação que estabelece quatro conjuntos de silogismos (conforme a posição do termo médio) e à indicação de regras precisas para a construção dos mais variados tipos de silogismos.

O rigor de Aristóteles em suas análises levou-o a determinar um princípio, já elencado por Parmênides: algo não pode ser e não ser ao mesmo tempo e sob o mesmo aspecto. Em outras palavras, não se pode ter uma tese verdadeira e falsa ao mesmo tempo. Trata-se do princípio de não-contradição, um dos quesitos mais importantes para o estudo de conjuntos de proposições em um discurso.

Frente à limitação imposta inicialmente pelo princípio de não-contradição, Aristóteles, e mais propriamente os pensadores medievais, criaram a regra da distinção. Ou seja, predicados opostos podem ser atribuídos ao mesmo sujeito, desde que se aponte a diversidade de aspectos para cada caso. Por exemplo, pode-se afirmar que J. B. tem 1,60 m de altura e também que ele tem 1,30 m de altura, sem ferir o princípio de não-contradição, caso se faça a seguinte distinção: 1,60 m em pé e 1,30 m sentado. 
O princípio de não-contradição foi e continua sendo um dos aspectos que mais suscita disputas entre analíticos e dialéticos. Enquanto os analíticos tomam esse princípio como quesito para descartar um discurso, a dialética considera a contradição como um princípio ativo e inerente a todas as coisas. (HEGEL, 1996, p. 74). Sobre tal discrepância, no entanto, algumas considerações devem ser apontadas. Em primeiro lugar, é importante esclarecer que 0 que os dialéticos chamam de contradição, corresponde, no quadro lógico dos analíticos, a contrários. Ora, proposições universais contrárias, mesmo no quadro lógico dos aristotélicos, podem ser ambas falsas, sem que se incorra em um erro lógico. Essa (que os dois debatedores admitam a falsidade de suas teses), como foi visto anteriormente, é a condição para se ter uma síntese e acontecer a dialética. A constituição morena de nossa população é um ótimo exemplo de que, entre negro e branco, existem outras possibilidades que não a exclusão de uma das partes.

Um segundo aspecto a ser esclarecido nas disputas entre analíticos e dialéticos é a necessidade que os primeiros possuem de terem um sujeito lógico, ao passo que na dialética, a resposta à pergunta pelo sujeito (quem faz a ação) remete, em alguns casos, ao Absoluto, em outros às estruturas econômicas de produção, mas nunca a algum indivíduo particular. Nesse sentido, CirneLima afirma que "fazer filosofia dialética é saber passar de um Eu estreito para outros Eus que, embora mais amplos, não deixam de ser Eu mesmo: o Eu que é Nós, o Eu que é natureza, o Eu que é o Absoluto" (1997, p. 232).

Independente da resposta que cada autor possa dar à pergunta pelo sujeito, normalmente oculto no discurso dialético, o fato é que uma tal resposta somente pode ser apresentada considerando-se a história, entendida como o processo de mudanças, na qual se tem o devir, por meio do conflito dos contrários, gerando sínteses e novos conflitos e, na qual se revela o sujeito do processo de mudanças. É por esse motivo que não é possível uma dialética de um fato ou de um objeto tomando-o de forma isolada da totalidade que 0 constitui, como ocorre no caso de uma análise experimental.

Entendidas enquanto modelos, pode-se dizer que tanto a dialética quanto a analítica, iniciadas no mundo grego, foram os grandes constituidores da cultura ocidental. A primeira vai de Platão a Marx, passando por Santo Agostinho, Escoto Eriugena e Hegel, entre outros; e a segunda vai de Aristóteles à atual Filosofia Analítica, passando, por exemplo, por Tomás de Aquino, Descartes, Kant, Frege, Bertrand Russell e Wittgenstein.

Em muitos casos, quando o termo dialética aparece na história, está associado à interpretação conferida por Aristóteles - lógica das possibilidades e forma de argumentação - e não como meio de conduzir à Verdade (episteme), conforme entendia Platão. Na Idade Média, por exemplo, a dialética que figura no trivium, juntamente com a gramática e a retórica, designa apenas uma parte da lógica aristotélica. Algumas exceções a essa regra, no período medi- 
eval, são Plotino e Escoto Eriugena. Após a Idade Média, até Kant, geralmente, a interpretação que se tem do termo é a aristotélica.

Com HEGEL, o termo dialética se afastará definitivamente da idéia de método de discussão (Aristóteles), sem, no entanto, render-se à concepção platônica de um método que permite chegar ao Sumo Bem. Diferentemente, Hegel concebe a dialética como sendo a maneira pela qual se tem o desdobramento do Absoluto (da Idéia) na história. Sob a ótica de Hegel, a dialética torna-se um olhar sobre o passado (Coruja de Minerva) e um método de explicação (explicar entendido como desfazer as dobras - plicas) de um desdobramento que se faz na história, rumo a um fim determinado (concepção teleológica do mundo).

Segundo Hegel, a história do Espírito apresenta uma evolução, mas não uma linearidade. Para traduzir a idéia de ruptura e continuidade contida no processo histórico, ele utiliza o termo Aufhebung, que tem vários significados na língua alemã. Significa dissolução - de uma assembléia, por exemplo; significa guardar, manter algo - um musse de maracujá na geladeira, por exemplo; e significa, também, elevar, colocar em um ponto acima - a foto colocada sobre a estante, por exemplo. Dessa maneira, o termo designa uma superação que conserva aspectos do que fora suprimido, constituindo algo novo em um nível mais elevado.

Com os jovens hegelianos inicia-se uma discussão acerca do caráter retrospectivo da dialética de Hegel. Apenas com Marx a dialética ganhará novos contornos em termos de aplicabilidade. Das diferenças que podem ser apontadas entre a dialética de Hegel e a de Marx, a principal é que, enquanto para aquele são as idéias (o Absoluto) que colocam a realidade, para este é a realidade material, entendida como os processos produtivos e os conflitos de classes, que produz as idéias (ideologias). Para Marx não é a idéia (o Absoluto) que se constitui na história por meio de contradições, mas relações sociais (formas de organização) que vão se modelando conforme os modos de produção. Nesse momento, talvez para enfatizar sua distância em relação a HEGEL, ele prefere referir-se ao seu trabalho com o termo Materialismo Histórico e não com dialética.

O afastamento de Marx em relação a Hegel pode ser notado também em expressões conhecidas como a sua 11a tese contra Feuerbach "os filósofos se limitaram a interpretar o mundo, diferentemente, cabe transforma-lo" (MARX, 1974, p. 59). Por meio dela fica indicada a necessidade de se ocupar com 0 presente e com o futuro e conferir ao sujeito (que se mantém coletivo) um outro significado no processo histórico, rompendo, nesse momento, com 0 necessitarismo próprio à dialética hegeliana. Em outros momentos, no entanto, também com Marx, tem-se uma teleologia (idéia de que a História caminha para um fim previamente determinado) e um necessitarismo, uma vez que considera certos desdobramentos como, por exemplo, o fim do capitalismo 
por suas contradições internas, a revolução proletária e o futuro comunismo, como necessários.

Algumas questões colocadas à dialética, no século XX, especialmente após as críticas de Nietzsche, estão ligadas justamente à idéia de teleologia e de necessitarismo. Nos dias atuais, não se acredita mais que haja um telos para o qual a história caminharia, tampouco crê-se em desdobramentos necessários aos conflitos presentes na história. Do ponto de vista dos dialéticos de hoje, tais questões não diminuem a importância da dialética; ao contrário, levam-na a uma renovação justamente no sentido de um engajamento na realidade que pretende transformar.

Da mesma forma como a dialética, também a analítica passa por uma série de mudanças. As mais significativas ocorrem no início do século XX, quando passa a ser identificada pela expressão Filosofia Analítica indicando um movimento, iniciado por G. E. Moore e B. Russell, na Inglaterra, cujas raízes encontram-se na tradição Empírico-Analítica e professa uma anti-metafísica e um anti-hegelianismo. Os desenvolvimentos mais conhecidos da Filosofia Analítica tem lugar com o Círculo de Viena (então denominando neopositivismo ou positivismo lógico) e com Wittgenstein, com quem ela ganha contornos de Filosofia da Linguagem (jogos de linguagem).

Independente das variações que sofrerá nos diferentes momentos, um aspecto da analítica que se mantém na Filosofia Analítica é seu caráter de análise. Em ambas não há o propósito de produzir realidade (ou mudá-la, como pretende a dialética) ou novos discursos sobre ela, mas analisar os discursos existentes, permitindo um posicionamento frente a eles, bem como uma verificação de sua sustentabilidade a partir de algum critério.

Por fim, mais do que apontar a riqueza encontrada no interior de denominações como a analítica e a dialética, e sinalizar para outras possibilidades de leitura e explicitação de mundo, interessa aqui retomar a seguinte questão: a partir do momento em que se tem uma concepção de mundo (de objeto de pesquisa), uma definição do que se pretende frente a ele e do grau de envolvimento esperado, a questão do método a ser "escolhido" deixa de se colocar, pois necessariamente, junto com essa forma de compreender o mundo, já se tem uma maneira de explicitá-lo. Nesse sentido, fins e meios não se separam, da mesma forma como não se separa uma tese de sua explicitação.

\section{Referências Bibliográficas}

CIRNE-LIMA, Carlos. Dialética para principiantes. 2. ed. Porto Alegre: EDIPUCRS, 1997.

GAMBOA, Silvio A. Sanchez. "A Dialética na Pesquisa em Educação: elemen- 
tos de contexto. In: FAZENDA, Ivani (org.). Metodologia da Pesquisa Educacional. 4. ed. São Paulo: Cortez, 1997.

GOLDSCHMIT, Victor. "Tempo histórico e tempo lógico na interpretação de sistemas filosóficos”. In: A Religião de Platão. 2. ed. São Paulo: Difusão Européia do Livro, 1970, p. 139 - 147.

HEGEL, Georg W. Friedrich. Wissenschaft der Logik. 4. Aufl. Frankfurt am Main: Suhrkamp, 1996.

IMBERT, Claude e outros. Filosofia Analítica. Lisboa: Gradiva, s/d.

LAKATOS, Eva Maria; MARCONI, Marina de Andrade. Metodologia Científica. 3. ed. São Paulo: Atlas, 2000.

MARX, Karl. Manuscritos econômicos e filosóficos e outros tex tos escolhidos. São Paulo: Victor Civita, 1974.

MORA, José Ferrater. Dicionario de Filosofía. 5. ed. Madrid: Alianza Editorial, 1986.

PLATÃO. A República. 8. ed. Lisboa: Caloustre Gulbenkian, 1996.

RITTER, Joachim; GRÜNDER, Karlfried. Historisches Wörterbuch der Philosophie. Basel: Schwabe \& Co Ag., 1989. 